\title{
Correspondence
}

\section{Correcting inaccurate assumptions underpinning Transforming Care in England}

John Taylor ${ }^{1}$ is an experienced responsible clinician looking after offenders with intellectual disabilities and/or autism presenting with complex needs. I can accept the perceptual position he has taken on some of the challenges outlined in his editorial. However, his assertion that underpinning Transforming Care is an assumption 'that the hospital is always bad, and community is always better' is inaccurate. We have explicitly said that some people will need specialist in-patient care, treatment and support at times. When this is needed, we should strive to deliver better quality care, a reduction in restrictive practices, therapeutic environments, improved patient experience and reduced lengths of stay. At the start of the national learning disability programme, we had a five-fold variation in the 'need for admission' to a mental health/learning disability bed across the country. This has now reduced to a three-fold variation. The National Health Service (NHS) Long Term Plan (www.longtermplan. nhs.uk/wp-content/uploads/2019/01/nhs-long-term-plan. pdf) is explicit about its focus on increasing investment in intensive, crisis and community support and improving the quality of in-patient care across the NHS and independent sector.

Jean O'Hara, National Clinical Director for Learning Disabilities, NHS England, Royal College of Psychiatrists; email: jean.o'hara1@nhs.net

\section{Conflict of interest}

I am the clinical lead for the national learning disabilities programme in England

1 Taylor JL Delivering the Transforming Care programme: a case of smoke and mirrors? BJPsych Bull 2019; doi: 10.1192/bjb.2019.3.

doi:10.1192/bjb.2019.27
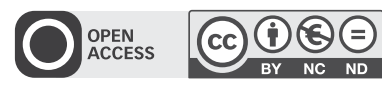

(C) The Author 2019. This is an Open Access article, distributed under the terms of the Creative Commons Attribution-NonCommercial-NoDerivatives licence (http://creativecommons.org/licenses/by-nc-nd/4.0/), which permits non-commercial re-use, distribution, and reproduction in any medium, provided the original work is unaltered and is properly cited. The written permission of Cambridge University Press must be obtained for commercial re-use or in order to create a derivative work.

Author reply: Jean O'Hara is correct in saying that I am a responsible clinician working with people with intellectual disabilities with offending histories and complex needs - in both in-patient and community settings. As such, my experience of the impact of the Transforming Care national plan is concrete and real rather than 'perceptual'.
It is nonetheless encouraging to learn that NHS England recognises that some people with intellectual disabilities and/ or autism need high-quality in-patient care and treatment at times. The question is, post Transforming Care, where are they going to receive it given the wholesale closure of specialist NHS services - including some rated by the Care Quality Commission as outstanding? The options would appear to be either the profit-focused private sector, or acute mental health in-patient units where the specialist care and treatment required is not available.

I note that $\mathrm{Dr}$ O'Hara doesn't refer to the data that indicate clearly that the Transforming Care national plan has failed to significantly reduce the number of people with intellectual disabilities and/or autism in in-patient facilities. Rather, she introduces a new metric of the 'need for admission'. This is not defined but seems to refer to admission rates. It is suggested that the national plan has been successful in reducing the variation in the 'need for admission' across the country. Given that a reduction in the geographical variation of admission rates could be achieved by closing beds in some areas whilst maintaining (or increasing) bed numbers in others, with no overall reduction in the number of beds across the country, one might wonder whether this is another case of smoke and mirrors?

Three-and-a-half years on, the Transforming Care programme has failed to invest the tens of millions of pounds in community services in England promised in the national plan. Can we then be comforted by the news that the NHS Long Term Plan 'is explicit about its focus on increasing investment in intensive, crises and community support', or is this just another example of 'jam tomorrow and jam yesterday, but never jam today' ${ }^{1}$ for people with intellectual disabilities?

John L. Taylor, Professor of Clinical Psychology, Northumbria University, UK. email: john.taylor@ntw.nhs.uk

\section{Conflict of interest}

I am employed by Northumberland, Tyne and Wear NHS Foundation Trust; however, the opinions expressed in this response are my own and do not reflect the views of the Trust.

1 Carroll L. Through the looking-glass, and what Alice found there. Macmillan, 1871.

doi:10.1192/bjb.2019.28

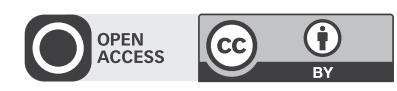

(c) The Author 2019. This is an Open Access article, distributed under the terms of the Creative Commons Attribution licence (http://creativecommons.org/ licenses/by/4.0/), which permits unrestricted re-use, distribution, and reproduction in any medium, provided the original work is properly cited. 